\title{
Liver Transplantation in Egypt
}

\author{
Mai I Mehrez* \\ National Hepatology and Tropical Medicine Research Institute, Egypt \\ *Corresponding author: Mai I Mehrez, Fellow of Hepatology, National Hepatology and Tropical Medicine Research Institute, Egypt \\ Submission: 漹July 31, 2017; Published: 些 November 13, 2017
}

\begin{abstract}
Liver transplantation is the best solution for patients suffering from end stage liver disease. The magnitude of liver disease in Egypt in remarkable due to HCV infection. The pool of donors does not cover the increasing need for this modality. Deceased program although it has been approved legally since 2010 but still not activated and the detailed regulations are not yet established due to resistance of some groups as religious and human rights. In this review, we show the progress of liver transplantation in Egypt since its start in 1991 and aiming to start the deceased program soon.
\end{abstract}

\section{Introduction}

Liver transplantation (LT) is currently the treatment of choice for patients with advanced chronic liver failure for which no other therapy is available [1]. In Egypt, there is no doubt that chronic liver diseases are amajor health concern. Hepatitis C virus (HCV) prevalence among the 15-59 years age group is estimated to be $14.7 \%$. Accordingly, Egypt has the highest HCV prevalence in the world. Today, HCV infection and its complications are among the leading public health challenges in Egypt [2].

In Egypt, the use of deceased organ donors is still prohibited, and as a result, some patients seek liver transplant abroad. Thus living-donor liver transplant is the only possible option for patients with end stage liver disease in Egypt [3]. The purpose of this article is to review the evolution of LT in Egypt and the current status.

\section{Historical Background}

In July 1989, Strong et al. performed the first successful transplantation of a liver graft from a living related donor; the donor was a 29-year-old woman and the recipient washer 17-month-old son [4]. Living donor liver transplant (LDLT) was first performed in Egypt in 1991 by the surgical team at the National Liver Institute (NLI), Menoufeya University, with the help of Prof. Habib. The longest recipient survival was 11 months.

The breakthrough was madein Dar Al-Fouad Hospital by starting the program of LDLT (August 2001), with Prof. Tanaka, Kyoto University, Japan. This was followed by Wady El-Neel Hospital (October 2001), NLI, Menoufeya University (April 2003) and Maadi Armed Forces Hospital (September 2003). By that time, there was increase in number of centers doing LDLT (13 centers) and increase innumber of LDLT cases $(2,500)$ with improvement of the results of LDLT [5].

\section{Indications}

Yosry et al. showed that hepatitis C related ESLD is the main indication for liver transplantation and represents $89.8 \%$ of cases in Egypt, while HBV and other indications (cryptogeniccirrhosis, Wilson disease, and glycogen storage disease) represent $5.1 \%$ and 5.1\% respectively [6] (Figure 1).

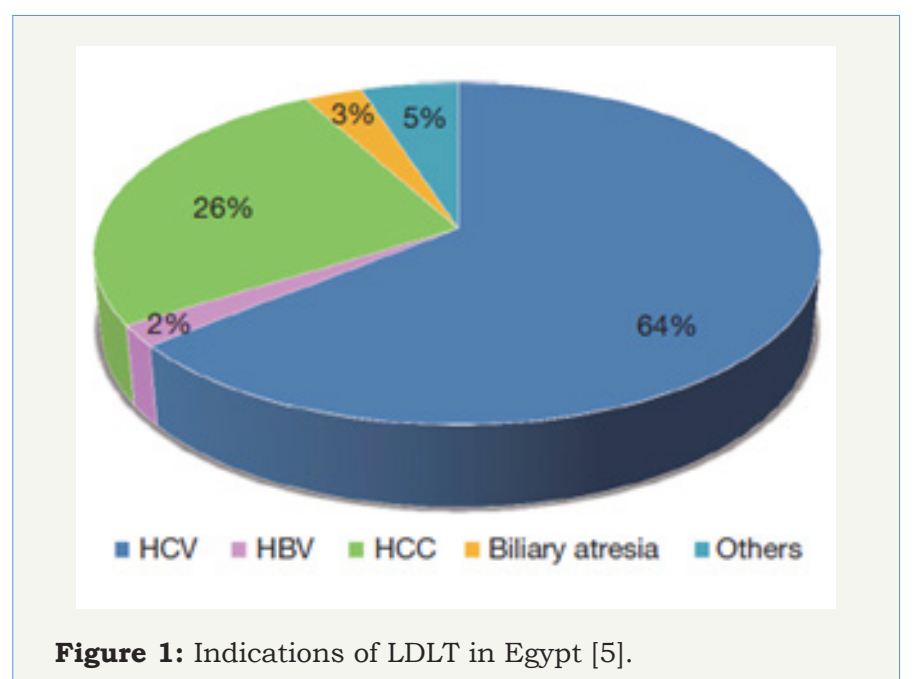

\section{Outcome}

Yosry and his colleagues showed in their study in 2008 that recipient and graft survivals were $86.6 \%$ at the end of the followup which was comparable to literature reports for deceased donor liver transplantation (DDLT) [7].

While in 2015 Gad et al. showed that the overall mortality was 75 (44.9\%). The incidence of in hospital mortality was $28.7 \%$ and its most frequent cause was SFSS $(6 \%)$, while the incidence of 
late mortality was $16.2 \%$ and its most frequent cause was sepsis (7.2\%). On the other hand, the overall 6-months, 1-, 3- 5- and 7-year survival of our patients were 109(65.3\%), 102 (61.1\%), 95 (56.9\%), 94 (56.3\%) and 92 (55.1\%) respectively [8].

\section{Complications}

The study done in National liver institute Menoufya in 2015 showed that the overall post-operative complication rate was $86.2 \%$, and this high rate occurred due to including all types of complications (single, multiple, minor, major, complications treated medically, by intervention endoscopy, radiology and that treated surgically).

There was a trend towards significant mortality among biliary complicated cases which reached $43.7 \%$. While vascular problems such as thrombosis and stenosis of the hepaticartery, portal vein and hepatic vein were $21.6 \%$. Small for size syndrome was the most frequent cause of in hospital mortality with incidence of $12.6 \%$ the second was sepsis $4.3 \%$. Other complications like renal impairment with incidence of $21 \%$, neurological problems in $26.3 \%$ did not affect survival.

Acute rejection which is a common cause of graft failure was $19.2 \%$. The higher incidence of acute rejection in our study occurred due to adjusting the immunosuppressant dose to their lower limit for fear of neurotoxicity and nephrotoxicity and to avoid the occurrence of sepsis. HCV recurrence $19.2 \%$ in our study. This low incidence was due to putting strict criteria for detecting HCV recurrence, these are the biochemical, serological and histological evidences of recurrence, so we did not mention that HCV recurrence occurred until the patient fulfill all the previous parameters [8].

\section{Conclusion}

LDLT is successfully done in Egypt with similar results worldwide. We hope this success encourages the start of a solid deceased program to cope with the patient needs.

\section{References}

1. Boraschi P, Donati F (2004) Complications of orthotopic liver transplantation: imaging findings, Abdomen Imaging 29(2): 189-202.

2. Mohamoud YA, Mumtaz GR, Riome S, Miller D, Abu-RLJ (2013) The epidemiology of hepatitis $C$ virus in Egypt: a systematic review and data synthesis. BMC Infect Dis 13: 288.

3. El-Meteini M, Fayez A, Fathy M, Abdalaal A, Safaan H, et al. (2003) Living related liver transplantation in Egypt: an emerging program. Transplant Proc 35(7): 2783-2786.

4. Strong RW, Lynch SV, Ong TH, Matsunami H, Koido Y, et al. (1990) Successful Liver Transplantation from a Living Donor to Her Son. N Engl J Med 322(21): 1505-1507.

5. Amer K, Marwan E (2016) Living donor liver transplantation in Egypt. Hepato Biliary Surg Nutr 5(2): 98-106.

6. Yosry M, Abdel-R, Esmat G, El-Serafy M, Omar A, et al. (2009) Recurrence of hepatitis C virus (genotype 4) infection after living-donor liver transplant in Egyptian patients. Exp Clin Transplant 7(3) 157-163.

7. Yosry, Esmat, El Serafy M, Omar A, Doss W, et al. (2008) Outcome of Living Donor Liver transplantation for Egyptian Patients with Hepatitis C (Genotype 4)-Related Cirrhosis. Transplantation proceedings 40(5): $1481-1484$

8. Gad EH, Al Sebaey A, Lotfy M, Eltabbakh M, Sherif AA (2015) Complications and mortality after adult to adult living donor liver transplantation: A retrospective cohort study. Annals of Medicine and Surgery 4(2): 162-171. 